ago we found a nest of the brown tail moth in a French importation. The caterpillars in this nest were alive and healthy, and were carried to maturity in the insectary. This is the only one we ever found. It does not seem possible that this was the only nest of live caterpillars of this insect which ever entered the state. As some experiments in eastern Canada seem to show, a very cold winter will kill the larvae. We often have very cold winters in Minnesota.

It would be a fascinating subject to think about and discuss what might have happened had Congress passed a quarantine act fifty years before 1912, with how many less pests would we have to contend today: or with how many less would we have to contend if Congress had passed a quarantine act in 1898 the year after Dr. L. O. Howard's recommendation. These are very interesting subjects but not all pertinent to the present. The pests that are here now are the ones we are interested in; these and their control, and the methods by which we can prevent any more pests entering the country are the subjects which most appeal to us at this moment.

Chairman Ruggles: The next paper on the program is by $\mathrm{R}$. W. Harned and H. H. Kimball.

\title{
THE SWEET POTATO INSPECTION SERVICE IN MISSISSIPPI
}

By R. W. HaRned and H. H. Kimball, Agricultural College, Miss.

So far as we know Mississippi was the first state to inaugurate a statewide compulsory sweet potato inspection service. For several years the necessity of such an inspection service had been felt. This need had been emphasized by the large losses due to preventable sweet potato diseases that were being distributed throughout the State in seed sweet potatoes and sweet potato plants, and also by the danger of carrying the sweet potato weevil into uninfested sections of the State.

We do not feel that the Mississippi State Plant Board has started anything new or deserves any credit for any originality in this matter. The idea probably originally came to us while reading about certified Irish potatoes in other parts of the country. Probably a year before the Mississippi sweet potato inspection service was started, the State Plant Board of Arkansas under the direction of their Chief Inspector, Professor G. C. Becker, was urging the use of certified sweet potatoes for planting purposes. In fact, Professor Becker had a well organized sweet potato inspection service, but it was entirely voluntary. Anyone in Arkansas who wished to produce certified seed sweet potatoes could 
have his potatoes and potato plants inspected by applying to the Arkansas State Plant Board and by paying certain fees. Early in the spring of 1920, while our plans for starting a sweet potato inspection service were still in a rather nebulous condition, the Cotton States' Entomologists had a meeting at Vicksburg, Mississippi, where in a personal conversation with Professor Becker we learned for the first time about the sweet potato inspection service in Arkansas and we immediately proceeded to adopt nearly the same system in Mississippi. Details of the Arkansas sweet potato inspection service may be found in Circular No. 9 of the Arkansas State Plant Board, Little Rock, Arkansas.

The chief difference between the two inspection services are that in Arkansas it is voluntary with the grower. A man may buy or sell certified seed sweet potatoes or may not do so and the growers of certified sweet potatoes must pay for at least a part of the inspection service. In Mississippi, it is illegal to sell or ship seed sweet potatoes or sweet potato plants that have not been inspected and certified. Every grower who expects to sell sweet potatoes for planting purposes must have his sweet potatoes and sweet potato plants inspected and certified. This service is paid for by the State and is rendered at no cost to the grower, except that he must pay for the numbered certificate tags that are issued at actual cost.

The sweet potato inspection service is very similar to the nursery inspection service. We adopted the numbered certificate plan that has been so satisfactory in our nursery inspection work, - one of the many excellent ideas that we copied from the State Plant Board of Florida. If at any time any serious disease or insect pest should be found attacking the sweet potatoes of any grower who has sold plants or potatoes for planting purposes, we can promptly locate all properties to which shipments have been made by this grower.

During 1921 each grower was required to send promptly to the Plant Board office a copy of the invoice accompanying each shipment of potatoes or potato plants. This invoice gave the name and address of the consignee and of the consignor, the quantity and variety of potatoes or plants and the number of the Plant Board certificate permit that accompanied the shipment. This was satisfactory except that there was no uniformity about the size, shape and appearance of the invoices sent in and there was often considerable delay in sending the invoices. To overcome these troubles, during 1922 the permit certificate tags will be made up of two parts each containing the same number. These parts will be divided by a perforated line so that they can be easily separated. Both parts will contain the same information-name and address 
of consignor and consignee, quantity and variety of potatoes or plants and permit number. The tag part containing the eye will be attached to the shipment and the other part will be mailed at once to the Plant Board office.

The chief aims of the sweet potato inspection service are (1) to prevent the further introduction and spread of the sweet potato weevil (Cylas formicarius), of Black-rot (Sphaeronema fimbriatum), and of Stem-rot (Fusarium batatatis) (2) to control, reduce and if possible in time eradicate these troubles from the state, and (3) to prevent the introduction and spread of any other sweet potato pests that occur in other parts of the world, or that we may not know of at the present time.

The inspection service has been given plenty of publicity through the agricultural, daily and weekly papers that circulate in the state, by the county agents and by the railroads. Several posters have been issued that have been put up in public places in all parts of the state. The first two posters were copied from the Arkansas Plant Board posters through the courtesy of Professor Becker. Later, posters illustrating black and stem rot and the sweet potato weevil were issued.

The sweet potato weevil is only known to occur in the four southernmost counties of the State and a separate eradication campaign against this pest has been conducted for several years in cooperation with the U. S. Bureau of Entomology. Satisfactory progress has been made in eradicating this pest.

Black-rot and Stem-rot are quite generally distributed over the State and for years had been causing increasingly larger losses each year. Some farmers had stopped raising sweet potatoes, as their losses from disease had been so great as to make it unprofitable to try to raise them. It was common to hear men say that they had lost $50 \%$ or $65 \%$ or even $80 \%$ of their potatoes because of black-rot. We believe that losses of this kind are now a thing of the past in Mississippi. One interesting instance came to our attention only a few days ago. In a certain community last spring, all the farmers except one planted certified seed and took all the precautions that are recommended to avoid Black-rot. There was one farmer who said he did not believe there was anything to all that foolishness about preventing diseases and went ahead without taking any precautions. This fall when the farmers in this community hauled their potatoes to the community storage house the only one who had black-rot among his potatoes was this one man who did not believe in the inspection service. In another county a man who did not believe in the inspection service went over into another state in his automobile and smuggled in his supply of sweet potato plants. This fall the 
diseased potatoes were so numerous in his field that he decided that it would not pay to even dig his potatoes. These men have probably learned to have a little respect for the inspection service.

Before seed sweet potatoes can be certified they must be inspected at least twice,-once in the field and once in storage. Potato plants to be sold must be grown from certified seed and besides these, seed must be bedded under the supervision of an inspector of the Plant Board, and must be inspected at least once not more than three weeks before any plants are removed from the bed.

The inspection service may be considered under three headings: (1) Field Inspections, (2) Storage Inspections, (3) Bed Inspections.

Field Inspections. A $10 \%$ infection of stem-rot at time of field inspection prohibits certification of seed. If less than a $10 \%$ infection of stemrot is found all diseased hills are dug up and both vines and tubers burned under the supervision of a inspector who advises the grower to treat diseased spots in the field in the same manner that he treats his potato frame and beds in the spring-i.e.: apply corrosive sublimate or copper sulphate solution. Fields showing less than a $10 \%$ infection of stem-rot at first field inspection are re-inspected just before the potatoes are dug for the purpose of destroying all hills developing infection after the first field inspection was made.

Storage Inspection. Potatoes that are to be sold for planting purposes must be separated from eating potatoes before inspector arrives. (We urge field seed selection at digging time and the storage of seed potatoes as far away from the bulk of the crop as possible.) If black-rot or stem-rot is found during the storage inspection, and the grower still desires to sell a part of his crop for planting purposes, he must cull out all diseased potatoes from his seed stock and arrange for a second storage inspection at a later date.

When the field and storage inspections of a grower's seed sweet potatoes have shown them to be apparently free of serious diseases and insect pests, application is made to the State Plant Board for Seed Sweet Potato Permit Tags. The application is accompanied by an affidavit covering a number of points, among them the following:

The grower agrees to use permit tags on all seed sweet potatoes that he disposes of within the State of Mississippi. He agrees to dispose of only such seed sweet potatoes as have been inspected by an agent of the State Plant Board, and found to be apparently free of serious diseases and insect pests. He agrees to carefully inspect all sweet potatoes that are disposed of for planting purposes, culling out every potato showing the least sign of disease. He agrees to destroy all culled potatoes by 
fire or to use them for eating purposes or to boil them thoroughly before feeding them to stock. He agrees to dip all seed sweet potatoes just before disposing of them for 10 minutes in a solution of corrosive sublimate-strength one ounce to 8 gallons of water.

BED INSPECTIONS. Beds must be made of soil in which sweet potatoes have never before been grown, and if old frames are used they, as well as implements used in preparing the beds, must be thoroughly disinfected. Sweet potato draws are certified under the following conditions:

Only such potatoes as have met the requirements for Mississippi certified seed sweet potatoes are used to produce plants to be sold or given away within the State of Mississippi. All certified seed used to produce plants are hand culled and disinfected immediately before bedding out, this is done under the supervision of an inspector of the State Plant Board. All beds of certified seed sweet potatoes are inspected by an agent of the State Plant Board not more than three weeks before plants are to be removed from the beds.

Growers outside of Mississippi must comply with the same standards met by Mississippi sweet potato growers before permit tags are issued that will enable them to ship into the state. The quarantine and parcel post inspectors located at about 20 strategic points throughout the state give us an opportunity to check very closely the movement of plants into and within the state. All diseased and uncertified plants are held up.

We believe that we have an effective inspection service and that the results have fully justified the hopes we had at the start.

Mr. Haseman: I should like to ask Mr. Harned if the inspectors shown on the map are full time inspectors or part time.

Mr. HARned: We hope they are full time inspectors. The legislature convenes next month and if they treat us as well as they did before, they are full time inspectors.

Mr. G. M. Bentley: We in Tennessee think this is a very important measure. We have a similar department, except possibly a little in addition; for example, supervising of the seed, seeing that the seed is dipped, the frames and so forth carefully treated, and that the plant beds have the proper environment.

Most of you know that the South is hard hit at this time. Cotton, farm products, and live stock are low in price, and the sweet potato is the one product not so affected. The demand for the slips is very great, not only in the state of Tennessee, but in the States of Arkansas and Mississippi, and the growers of Tennessee are intensely interested in these requirements. There are four counties in the state which, if they 
pass inspection, can live upon the millions of slips shipped out. Our growers consider it a very important step in the agricultural problem, and this is something too that will influence a great many of the Northern states, since the sweet potato has been found to grow well, and profitable yields have been made in that section.

I think we should all express our confidence in the measures adopted by Mr. Harned in the state of Mississippi.

Chairman Ruggles: If there are no more remarks, we will pass on to the discussion of a paper presented at the Chicago meeting by H. F. Dietz, "Some Problems in Greenhouse Inspection in Indiana."

Mr. SASScer: I purposely put this paper on the program in the hope that it might provoke some discussion. Unfortunately, Mr. Dietz' paper was read last year at the end of the session, and there was little or no time for discussion.

I don't know how much problems of this kind affect state inspectors, or how far you attempt to go into inspection of materials distributed from greenhouses. We in Washington, however, are seriously concerned about this problem.

As many of you know, the Department of Agriculture is constantly introducing new plants from remote parts of the world. During the past ten or fifteen years we have intercepted many insects new to this country, and it is impossible to tell what would have been the result if they had been allowed to become established.

Our practice is to examine this material carefully in the inspection house upon arrival, and if there is the slightest doubt as to whether there is any danger, or if an insect new to us is found, the material is either burned, fumigated, or otherwise treated, and grown in what we style a "quarantine house." As soon as the danger has disappeared, this material is allowed to go to the field station at Bell, Maryland. We have taken the stand that it would be taking an unnecessary risk to allow material to leave the Bell greenhouses without an inspection at the time of shipment.

I might say that the greenhouses at Bell, at the present time, so far as we know, are infested with only the common greenhouse insects, but it frequently happens that we have a new pest under our eyes for six or eight months and do not recognize it as such. For that reason we are carefully inspecting the plants, not a month or seven weeks before, but at the time of shipment.

Temperature conditions in a greenhouse are comparable to the tropics. An inspection today is not good two weeks hence. I should like to have some expression as to whether or not the inspectors representing the 
various states at this meeting are of the opinion that we are taking unnecessary precautions. Would you be willing to accept the material which is distributed from the greenhouses in question with one inspection a year, or two or three inspections a year; or do you think we have adopted the right policy in inspecting at the time of shipment?

If we are going to ship material from a greenhouse, what kind of a certificate should we use? Are the state inspectors going to accept qualified certification? Would you accept plants from us if you knew they were infested with the common greenhouse insects? As most of you no doubt know, we now have a law in the District of Columbia which requires that all plants entering should be inspected and certified. We have an inspector at the post office, the express office, and the freight office, and during the past two months one hundred and twenty-two shipments have passed through the post office and express office which did not bear certificates of inspection, and thirty-five of these shipments were infested with common greenhouse insects such as the common mealy bug, greenhouse white fly, etc.

I think I am safe in assuming that very few, if any, of the states are inspecting, and if they are, they are not certifying material which is . distributed from greenhouses.

Mr. F. N. Wallace: I would like to ask Mr. Harned if they are going to pay attention to greenhouse stock down in Mississippi.

Mr. Harned: All plants coming into the state have to go to one of the parcels post inspection stations and are there inspected. We have six of them in the state. Our quarantine inspectors get most of the things that come in on trains, greenhouse plants included.

Mr. J. J. DAvis: At a meeting at La Fayette last winter, of the entomologists of Missouri, Illinois, Ohio, and Indiana, this matter was briefly discussed, and in our mimeographed report we made a statement regarding greenhouse inspection work. I don't recall the exact statement, but it was to the effect that very probably we could divide the insects of the greenhouse into two distinct classes-those generally distributed throughout the United States, and those which had a comparatively local distribution. In discussing this matter, it seemed desirable that those with local distribution should be restricted; that is, that plants infested with the insects of local distribution be restricted from shipment, and that restrictions should also apply to our common insects where the infestation was serious. But where the infestation was very light and normal, there probably need be no further restrictions on shipments from state to state. 
Mr. Sasscer: Mr. Harned, do you certify greenhouse stock?

Mr. Harned: In Mississippi at the present time we are inspecting the greenhouses. If we find anything of a serious nature, we quarantine that greenhouse until it is cleaned up. If we find any of the common insects very abundant, we require them to clean up before they can continue selling plants. But we are not certifying any of them at the present time. We have that matter under consideration and we are doubtful as to the best way of handling it.

Mr. WaLlace: Is the date of your inspection put on the shipping tag?

Mr Harned: We are not issuing shipping tags to the greenhouses. We are inspecting them and letting them do business locally. If they are shipping things out by mail, they have to have a permit to do so, and that is also true with express. But we are letting them sell locally without permits.

Mr. WALLACE: We inspect our greenhouses if a man wants to ship, but I will be perfectly frank in saying that the inspection tag, when it says that it is free from insect pest or plant disease, doesn't mean a thing. It means that we were reasonably sure that there was nothing injurious at the time we inspected.

But as Mr. Dietz made plain, a man might bring in something from another greenhouse the very next day and reship it under his tag. It is not only in Indiana but I think that thing is happening in all of the states. We don't want to start anything in Indiana and penalize our greenhouse men; and if it is not feasible with all the states we don't want to start it. I can't stop our men from shipping. They send up to Chicago and get the plants there. Or, as happens now, we can sell to a broker in Chicago and he resells to another broker, who ships it out and the man who buys it doesn't know where it comes from.

Mr. P. A. GlenN: We are puzzled in Illinois to know what to do with our greenhouses. Our law eliminates greenhouses from inspection and they are not required to be certified, but in some of the states they require certificates in order that our greenhouse men may ship stock into those states. One particular state has asked me to issue to certain greenhouses a certificate covering a year. I hardly see how a certificate could be issued on a greenhouse covering a year. They really ought to be inspected every two or three weeks, or every shipment that goes out ought to be inspected. Every shipment ought to have an effective inspection. But it has been our practice in Illinois, when greenhouses wanted to ship to another state where they require inspec- 
tion, to issue to our greenhouses a certificate reading like this: that they are practically free from the usual greenhouse pests and are apparently free from danger.

Of course, if a greenhouse has scale all over its palms, we refuse to issue them a certificate at all for palms. Or, we require them to agree not to ship any palms under a certificate we give them, and the certificate will apply only to stock in their greenhouses which seems to be free from scale or insect pest. We issue certificates to only those greenhouse owners who seem to take all the reasonable precautions to keep down the common insect greenhouse pests. It would be an awful job in Illinois to inspect every shipment that is sent out from greenhouses; in fact, it would be impossible.

Mr. T. J. HeadleE: I have felt for a number of years that the handling of the greenhouse stock situation should be given attention, and if Mr. Sasscer believes that the information that we now have on the different species of insects as to dangerous character, has gone far enough, I would like to make a motion that a committee be appointed, to throw this whole matter into some sort of definite shape for consideration at the next meeting. But I would like to have Mr. Sasscer answer the question first, as to whether he feels that the information along this line has gone far enough to permit reasonably fundamental action.

Mr. Sasscer: Doctor Headlee has asked a question that I don't believe I am competent to answer. If anyone had told me several years ago that the strawberry root worm would have become a rose pest in greenhouses, I would have been inclined to doubt him. Take the chrysanthemum midge for example. We fought desperately to keep it out of the Washington greenhouses, but it finally became established.

The great difficulty, it seems to me, is to determine what is an injurious insect in a greenhouse. Some five or six years ago the Bureat of Entomology initiated a project for the purpose of studying insects infesting ornamental plants in greenhouses, and a large mass of data has been assembled. Previous to undertaking this problem, Mr. J. J. Davis had been working up a bibliography of greenhouse insects, and he was generous enough to turn it over to us. However, there are a great many insect pests in greenhouses at the present time of which we know little. I am afraid that I am not in position to say that we know enough about greenhouse insects to lay down a definite rule that will hold for five or ten years.

Mr. HeadleE: I believe I will make the motion anyway, because we are in very much the same boat in all lines of insect work. I don't 
know as much about them as I should. So I move that a geographically representative committee be appointed by the Chair with Mr. Sasscer as chairman, to take this matter under consideration and see whether any general rules, fundamental principles and recommendations can be laid down, this committee to make its report at the next session of this section.

Mr. S. B. Fracker: I second the motion. A number of our men in Wisconsin keep a little outside shrubbery in order that they may be entitled to carry a nursery inspection certificate, and they attach it to greenhouse plants when requested to do so by the express agent. This is true particularly of inter-state shipments. The problem, we have felt, was a serious one, not only owing to the dangers from some of the insects mentioned by Mr. Dietz, but in other ways. For example, the orchid weevil, Cholus cattleyae, has been distributed from one greenhouse to another by means of stock, and its distribution could probably have been prevented if inspection certificates had been required. It is an insect which is perfectly ruinous in the orchid houses when it once becomes established.

The motion of Mr. Headlee, seconded by Mr. Fracker, was voted upon and carried.

Chairman Ruggles: The next paper on the program is "Important Foreign Insect Pests Collected on Imported Nursery Stock in 1921." by Mr. E. R. Sasscer.

\section{IMPORTANT INSECTS COLLECTED ON IMPORTED NURSERY STOCK IN 1921}

By E. R. Sasscer, Washington, D. C.

Eyclusive of bulbs and seeds, 27,507,929 plants were introduced during the fiscal year 1921 from all foreign countries in compliance with Regulations 3 and 14 of Quarantine 37 . Of this number, 21,172,049 plants arrived from France, the remainder being distributed among all other countries exporting to the United States. In spite of the emphasis which has been repeatedly made regarding the necessity of shipping only plants free from soil or earth, a number of shipments of plants, the roots of which were in part embedded in soil, arrived. Moreover, in several instances the soil included in the matted roots of Astilbe from Holland was found to be infested with the larvae of Brachyrhinus sulcatus Fab. which would have escaped the notice of the inspectors if the soil had not been detected, removed, and carefully 